\title{
Closure planning and decommissioning of tailings storage facilities
}

\author{
K.E. Bennett Outback Ecology, Australia \\ H.W.B. Lacy Outback Ecology, Australia
}

\begin{abstract}
A major driver for improved planning in closure and decommissioning of tailing storage facilities (TSFs) is the numerous TSF legacies that exist around the world. Tailings are a combination of any remaining process water and the fine grained solid material remaining after the recoverable metals and minerals have been extracted from the treated ores and placed in a containment area. The physical and chemical composition of tailings varies with the nature of the material being processed, and the process itself. These differences, along with the location of the operation, will dictate the level of management required for the tailings and for the TSF during construction, deposition and closure.

Tailings may be stored in a variety of ways, depending on their geochemical properties, the site topography, climatic conditions and the socio-economic context in which the mine and mill operations are located. TSFs are often viewed as the most difficult issue to resolve in mine closure. This can be mitigated by ensuring tailings closure planning occurs progressively throughout the life of the mine and a robust decommissioning process is followed. It is imperative that closure planning is an integral component of planning, design, construction, operations, closure and decommissioning.

The development of leading practice tailings management is becoming increasingly more rigorous both nationally and internationally. The importance of designing a sustainable TSF landform and managing construction with the end in mind is recognised within the May 2011 ANCOLD Draft Guidelines on Tailings Dams - Planning, Design, Construction, Operation and Closure.

The 2011 ANCOLD Guidelines highlight the important principle of designing, constructing and operating a TSF with an aim to an eventual closure strategy that will allow a safe and stable structure to remain following the completion of mining operations. Post-closure, a TSF must be able to cope with stochastic events and change likely to be encountered over an extended period determined as per the design life, potentially of 1,000 years or longer.

This paper will link the 2011 ANCOLD Guidelines to the critical factors that impact on the decommissioning and final rehabilitation of a TSF, including the opportunity to use risk assessment techniques to identify (design out), and manage closure challenges and risks at the beginning. Robust decommissioning planning as a part of tailings management will be discussed, increasing the awareness that closure is a process not an event.
\end{abstract}

\section{Designing a sustainable TSF landform and the consequences of poor planning}

The most widely accepted definition of sustainable development is provided in the United Nations World Commission on Environment and Development (UNWCED, 1987) landmark report 'Our Common Future' (the Brundtland Report) as "development that meets the needs of the present without compromising the ability of future generations to meet their own needs". The ANCOLD (2011) Guidelines provide additional advice to designers intending to achieve sustainable development as defined by the Brundtland Report. 
A core principle in sustainable development is the 'precautionary principle', which is simply stated in the 1992 Intergovernmental Agreement on the Environment as: "where there are threats of serious or irreversible environmental damage, lack of full scientific certainty should not be used as a reason for postponing measures to prevent environmental degradation" (DEWHA, 1992).

TSFs must be designed to safely contain water and tailings in a dynamic environment, not only during the operational life of the mine, but also for many years post closure. The mining industry is practicing 'adaptive management' in response to the TSF failures and incidents in recent decades; the International Commission on Large Dams (ICOLD) Bulletin 121 (2001) identified the main causes of failures and incidents as:

- Lack of control of the water balance.

- Lack of control of construction.

- A general lack of understanding of the features that control safe operations.

Specific to wall failures the main causes were (in order of prevalence):

- Slope instability.

- Earthquake loading.

- Overtopping.

- Inadequate foundations.

- Seepage.

Thanks in part to the increasing awareness of environmental issues, there is considerable literature relating to the environment and sustainable development (DRET, 2011). Environmental disasters such as those that occurred at the Ok Tedi Mine (and the Fly River), the Mt Lyall Mine (and the Derwent River Estuary), Rum Jungle (and the Finniss River), do not reflect current leading practice tailings management. The knowledge gained from incidents which have resulted in catastrophic damage to downstream land, property and ecosystems is helping to develop leading practice tailings management.

Adopting leading environmental management practices on mine sites makes excellent business sense. There is a strong business case for planned versus unplanned closure; unplanned closures are not cost effective and often result in sub-standard rehabilitation outcomes, as these works are remedial rather than integrated with mine planning. The failure or poor performance of a TSF can have a profound impact on the corporate bottom line. The cost of leading practice tailings management systems is more than offset by the reduced risk of a major incident.

Existing guidelines such as 'Tailings Management' (one of a series of publications outlining Leading Practice Sustainable Development Program for the Mining Industry published by the Australian Government Department of Industry, Tourism and Resources) (DITR, 2007) are supported by the 2011 ANCOLD Guidelines. 'A Guide to Leading Practice Sustainable Development in Mining' (DRET, 2011), the latest publication in this series by the Department of Resources, Energy and Tourism (DRET) (formerly DITR), and the Draft ICOLD Bulletin 153 on Sustainable Design and Post-Closure Performance of Tailings Dams (ICOLD, 2010), reinforce many of the parameters described in the 2011 ANCOLD Guideline.

One aim of the 2011 ANCOLD Guidelines is to provide a single base document that supports the DITR (2007) publication and others like it, with engineering detail that can be accepted by all relevant government authorities, and national and international companies involved in TSF development, allowing them to undertake design and construction consistent with leading industry practice (ANCOLD, 2011). 


\section{Importance of risk management during planning, design, construction, operation and closure}

Planning and design decisions can have long-term consequences for the environment, future land uses, community health and safety that will impact upon the mine closure and completion process. For example: poor foundation construction for a TSF can lead to exacerbated long-term seepage and potential groundwater contamination.

The ANCOLD Guidelines introduce 'the observational approach' to design evolution. The design is based on 'best estimate' conditions (on the basis of available data), and the observational approach is utilised to check estimated parameters (which can be progressively refined as real data becomes available). If the 'best estimate' assumptions are incorrect upgrade measures might be required following start-up; the observational approach is used to decide if and when any upgrade measures need to be constructed. However, it is essential to react to changes well before they become a serious problem (ANCOLD, 2011).

The ANCOLD Guidelines (2011) state that "the objective of planning is to ensure a commitment to managing an appropriate level of risk during all phases of the life cycle of a tailings dam, including concept development, design, construction, operation, decommissioning, rehabilitation, ongoing monitoring and the extended post-closure period."

There are many definitions of risk. Best Practice Environmental Management in Mining (Environment Australia, 1999) defines a hazard as a potential cause of harm, and risk as having two dimensions likelihood and consequence, which defines risk as the likelihood of actual harm. Risk analysis allows quantification of the options, and of the likelihood, consequences and costs of failure. The AS/NZS ISO 31000:2009 Risk management - Principles and Guidelines provides a generic guide to managing risk and the key elements of the risk management process.

Studies conducted by Envec, Environment Security Initiative (2005) found that 'the dominant hazards posed' in relation to mine legacies, are from tailings impoundments. Pollution is mobilised from these impoundments through a number of mechanisms such as from solid airborne transport (tailings dust can contain heavy metals and toxic compounds), mass movements of tails in liquid or semi liquid form, and waterborne as suspended solids and dissolved materials.

Risks should be kept below levels that place an undue exposure to hazards on third parties or the environment; and consideration should always be given to the consequences of failure of the TSF. Major TSF failures may be relatively infrequent, but the consequential harm can be enormous. Past failures have led to loss of life, catastrophic environmental damage, public outrage, restrictive regulatory intervention and associated financial losses and costs for the company responsible. There are significant measurable financial, reputation and sustainability benefits associated with achieving leading practice tailings management that effectively manages the potential risks associated with tailings dams during and after their operating lives (ANCOLD, 2011).

ANCOLD (2011) recommend that an individual consequence assessment is undertaken for each of the different phases of the TSF life. For example, erosion would be readily repaired during operation but could become a potential mechanism for large-scale failure post-closure when limited maintenance is likely. Similarly, seepage of contaminated water can be readily collected and treated during operation but could lead to significant environmental impact following closure. The impact of large scale failure of a TSF could increase significantly with time as the structure increases in scale and height. The Consequence Category should be established using the methodology described in the ANCOLD, 2011 Consequence Guidelines. The critical input to determining the Consequence Category is the assessment of the consequences of failure (ANCOLD, 2011).

A risk management approach throughout the life of the facility can effectively minimise, manage and control key risks. Potential design limitations and uncertainties can be mitigated if the outcomes of risk 
workshops are used to drive decisions on the future direction of the project. Beneficial risk treatments may include:

- Avoiding the risk by deciding not to start or continue with the activity that gives rise to the risk (where this is practicable).

- Eliminating the risk (or specific hazards) through design.

- Reducing the likelihood of the negative outcomes. For example, through stringent construction quality control, and through implementation of an effective surveillance and response plan.

- Reducing the extent and/or severity of the consequential impacts, including preventative measures such as increasing freeboard or post-event mitigation through emergency response plans.

- Sharing the risk (win-win) such as backfilling a neighbour's mine void (ANCOLD, 2011).

Irrespective of the detail and quality of the design, failures can occur if any element of the TSF (e.g. drains, filters) are not designed, constructed and operated in accordance with the primary intent of controlling and managing risk (ANCOLD, 2011).

The TSF design should aim to integrate all the processes, systems, procedures and other activities required for a safe and economical TSF. The primary objectives for the design of a TSF are:

- The safe and stable containment of tailings and contaminants.

- The safe management of decant and rainfall runoff.

- The management of seepage.

- The ability to achieve long-term effective closure, leaving no unacceptable environmental legacy.

- The meeting of these objectives in a cost effective manner (ANCOLD, 2011).

It is well understood that basic tailings properties (both geotechnical and chemical), storage requirements, tailings production rates and delivery conditions, (how they will change with time, and the potential for planned or unplanned changes to the delivery conditions), are central in the development of a TSF design. The full cost of tailings disposal from conceptualisation to final decommissioning and rehabilitation, including long-term post-closure maintenance considerations should be considered in the planning stage.

Identification of issues early in the mine life can guide closure planning toward a particular design and end point. For example, early characterisation of tailings and cover materials should be undertaken to ensure that they do not have the potential to create an adverse impact or prevent successful revegetation being achieved during mining or at closure. The requirement for characterisation should continue during the operation of the mine, particularly where the ore grade and mine plan change in response to altered market conditions (DRET, 2011).

During construction it is essential that construction contractors and personnel understand the implications that their activities may have for the eventual closure of the mine. As construction proceeds, it is important that an accurate record of all works is kept, (including field and laboratory testing), in order to provide documentation of compliance with the design drawings and specifications. Deviations from the drawings or specifications should be documented in 'as-built' records (DRET, 2011). These records are also essential for ongoing management of the TSF. The construction records together with monitoring data form the basis of the design of subsequent stages.

Changes commonly occur throughout the operational life of a project, in response to unforseen conditions, which can affect the operation of the TSF. If the observational approach is adopted it is critical that the process of verifying design assumptions during the operational stage is undertaken, and there is a quick and effective response to signs of distress or impending failure (ANCOLD, 2011). 
A TSF design plan may evolve over a number of years during operations; accordingly the operator needs to provide a methodology for a design review process and operational constraints have to be identified and incorporated into operational procedures. The operational procedures for the TSF should include provisions for regular inspection, monitoring and evaluation (and documentation thereof). Conditions can develop during operations which, if not detected early, could lead to loss of containment or unsuitable conditions for undertaking plans for extension or closure of the facility. The principal aim should be to operate a TSF towards achieving the closure and intended use after closure.

Progressive rehabilitation, where possible during operations, enables rehabilitation work to proceed while there is an operational cash flow, and management and resources available. Progressive rehabilitation can also reduce the cost of financial assurance required by regulatory agencies (DRET, 2011). A TSF must be designed with mine closure in mind, so as to create a permanent, maintenance free deposit that poses little, if any, unacceptable long-term environmental risk. Leading practice tailings management will also minimise the time required for post-closure monitoring and maintenance.

Good planning and design requires alignment between the TSF plan and the mine plan, such that if there are any changes to the mine plan, the TSF plan is reviewed and revised, if necessary. Consideration should be given to:

- Integration with the mine plan and schedule in developing the tailings disposal methodology. For example, utilising or stockpiling topsoil and waste rock for construction of containment wall raises and covers.

- Location of the TSF to avoid sterilising mineral resources or contaminating water resources.

- Availability of suitable embankment construction materials and surface covering materials.

- Change management. For example, increases in processing plant throughput impact storage requirements for tailings and water, as well as the rate of rise of the tailings surface, can have implications for tailings strength and stability.

- Reprocessing of tailings. Some tailings may contain valuable minerals and therefore a management objective may be to provide interim storage until economic recovery becomes feasible (DRET, 2011).

Decommissioning and closure must be considered during the planning stage to ensure that the post-closure performance will meet stakeholder expectations and regulatory requirements. The cost of TSF decommissioning can be estimated at an early stage so financial provisions can be set aside; it is particularly important to ensure there are appropriate funds available to close the TSF in later years when revenues are diminishing. It is imperative that costing is realistic and not compromised by conflict of interest.

Adequate planning associated with good tailings management and the use of sound technical approaches early in the life of the facility significantly reduces the cost of decommissioning. For example: applying leading practice management techniques at the earliest stage of development, and in designing and operating the TSF to optimise closure can result in the avoidance of significant earthworks expenditures to re-establish stable landforms and drainage systems.

Closure and Rehabilitation Planning should ensure that the tailings disposal area is left in such a way that it is able to:

- Maintain an acceptable impact on the environment.

- Be structurally stable.

- Be resistant to deterioration through erosion or decay.

- Be compatible with the surrounding unmined landform. 
- Be functionally compatible with the agreed post-mining land use (ANCOLD, 2011).

The above criteria should apply over the perceived time frame of the post-closure period, which may be indefinite. If there is no defined post-closure design life, ANCOLD recommend adopting 1,000 years as a reasonable period as being considered 'in perpetuity'.

\section{Active planning and actions during the mine life}

There are a number of factors to be considered when preparing to decommission a TSF. The hostile nature of tailings stored in many facilities requires that decommissioning and subsequent rehabilitation is carefully planned and executed. Environmental or climatic conditions must be considered and potential problems likely to affect the long-term integrity of rehabilitation works taken into account (Lacy and Ward, 1998). The factors that influence the rehabilitation of a TSF are:

- Ore type and its geochemistry.

- Process used for ore extraction.

- Process water quality.

- Type of disposal technique.

- Environment where the TSF is situated.

- Compliance requirements (including performance objectives, criteria and indicators).

- Potential final landform.

- The final land use.

- The environmental aspirations of the company.

- The potential for post-closure environmental impact.

As with all reclamation processes a staged program is required to capture all decommissioning issues, and a path similar to that developed and used by the authors is suggested in Figure 1.

\section{$4 \quad$ Regulations, stakeholders and closure}

Each site has specific commitments and conditions relating to TSF operation and closure, and each county has its own regulatory guidelines, legal information and related literature on TSF closure. Within Australia, regulation of TSFs comes under State Government mining legislation.

The environmental operators and closure personnel need to have a clear understanding of their regulatory commitments and conditions related to the TSF. It is not uncommon for a mine site to discover at the end of the mine life that the regulatory commitments and conditions related to closure conflict with their mine closure plan. In many situations this can easily be avoided by reviewing statutory conditions and commitments prior to initiating any closure design. However, this is not to say commitments made ten years previously cannot be superseded as they are no longer relevant due to improved closure techniques and best practice. Discussions with relevant government departments can lead to modifications of conditions to suit an improved closure plan from that that was proposed during the initial mine approval period (Lacy and Barnes, 2006).

Stakeholder engagement stands out as one of the most fundamental principles for effective mine decommissioning. Key stakeholders include the land owners, surrounding community, local government and regulatory government agencies, and/or others that are affected by, or have an interest in the mine closure. The objective is to engage with the key stakeholders on issues of concern such as: end land use; completion criteria; rehabilitation monitoring programs; and potential environmental impacts. There is also a requirement to build and maintain a community appreciation for the post closure conditions that will prevail. 
The three principals that will result in effective stakeholder consultation are:

1. Identify key stakeholders and provide appropriate information for their needs.

2. Establish consultative processes to ensure ongoing engagement with the community.

3. Respond to community concerns in a transparent and effective manner.

Mining is generally a transient activity, which is often responsible for substantial changes in both the community and the environment in which it operates. Stakeholders' interests often precede the mining operation and remain long after mining ceases. These interests often relate to alternative ongoing land uses which can include retention of infrastructure for public use and the maintenance of sustainable nonmining-based communities (WMI, 1994).

Many factors play a large part in reclamation planning: and these include company environmental policy, society's expectations of industry, an understanding of the reclamation requirements and policies of the principal regulatory authorities, and the varied and diverse needs of other stakeholders. Although all these anthropocentric factors drive reclamation planning, ultimately it is the final land use that has to be the prime consideration for reclamation. In some cases this may have values that are not purely confined to immediate human land use needs, but are those of the broader ecosystem in which the tailings remain stored (Jones et al., 2006).

\section{$5 \quad$ Decommissioning - easy or difficult?}

TSF closure is a process of closing down a TSF with the broad objective of leaving the facility safe, stable and non-polluting with little need for on-going maintenance. As stated in the Strategic Framework for Tailings Management (MCMPR and MCA, 2003) there are a number of objectives that need to be considered when planning the final landform, these are:

- Containing/encapsulating tailings to prevent leaching into ground and surface waters.

- Provide surface drainage and erosion protection to prevent surface water transporting tailings from the storage area.

- Providing a stabilised surface cover to prevent wind erosion.

- Designing the closure to minimise post-closure maintenance.

The 2011 ANCOLD Guidelines recommend that a TSF Closure/Decommissioning Plan be prepared, and costed, as part of the initial project development and included in economic, social and environmental analysis of the project viability. The Plan should then be kept live and regularly reviewed and updated as the project develops through design, construction, operation and potential changes in scale and direction.

The authors use a well-established decommissioning approach adapted from Lacy and Campbell (2000) and believe tailings decommissioning should be a staged approach. This ensures an appropriate and acceptable decommissioning procedure is followed (Figure 1), and makes the process easy rather than difficult. This approach involves a logical sequence of:

1. Stakeholder discussions and site visit and document review.

2. Sampling, investigations and research as required to define tailings and rehabilitation materials and then in association with other specialist sub-consultants (where required) resolve closure issues.

3. Preparation of the Conceptual Decommissioning Plan for submission to Regulators.

4. Decommissioning of the TSF and preparation of a Final As-Built Decommissioning Report.

5. Monitoring and sign-off. 


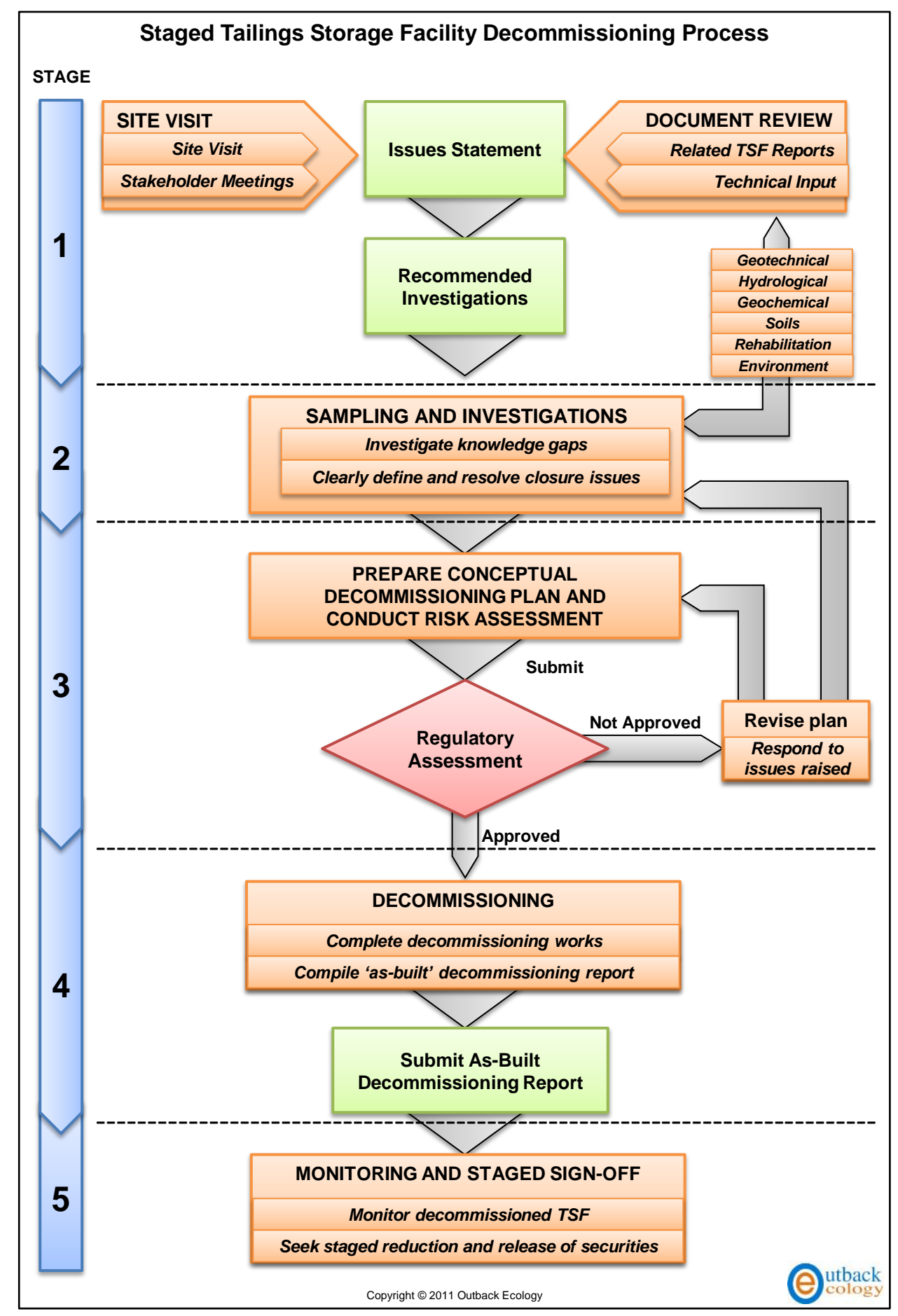

Figure 1 Staged tailings storage facility decommissioning process

Stages One and Two (Figure 1) provide the foundation information that guide the TSF decommissioning process toward an appropriate closure strategy. A review of literature is critical and should also incorporate a review of the conditions and commitments related to TSF closure and to ensure compliance with regulations.

The collation and summation of all literature relating to the TSF should provide a solid understanding of the TSF and expose information that is missing, and the investigations that are required before an informative and appropriate closure strategies can be finalised. It is not possible to properly decommission a TSF without adequate knowledge and an understanding of the tailings properties. 
Each TSF is unique in terms of its mineralogy, process, management, design, climate and location, therefore it is expected that closure planning, design and decommissioning solutions may also be unique to each facility. Closure options need to be reviewed on a case by case basis as there are likely to be specific issues to be addressed in each case. Some considerations include:

- Landform reconstruction options will be influenced by climate.

- Water management approach will be driven by climatic regime and should consider possible climate change.

- A water or saturated soil cover might be appropriate in a wet climate to maintain the tailings saturation when required to prevent oxidation and the production of contaminants in seepage.

- A rainfall shedding cover may be appropriate in a wet climate to minimise infiltration and ongoing seepage (incorporating a spillway and sediment collection pond).

- A store/release cover might be appropriate in a moderate or dry climate, possibly including a sealing layer.

- Stakeholder engagement is essential.

The ANCOLD Guidelines recommend that the following issues be addressed in the Plan:

- Final landform and its relationship to embankments and storage geometry.

- Earthworks plan and staging.

- Materials handling and stockpiling.

- Temporary works.

- Physical and chemical stability of the tailings facility and durability of control structures.

- Cover types for tailings.

- Consequences of extreme environmental conditions (e.g. drought, flood, fire, earthquake).

- Access control.

- Structural integrity.

- Geotechnical stability.

- Ongoing settlement.

- Erosional stability, including sedimentation and its influence on drainage.

- Surface drainage works (noting that these concentrate flows, making them difficult to sustain without rigorous design, construction and ongoing maintenance).

- Surface treatment to minimise erosion (via rock cover and/or vegetation), while sustaining vegetation.

- Monitoring and audit requirements for the closure process and aftercare.

Stage Three of the staged decommissioning approach (as discussed previously) involves submission of the Conceptual Decommissioning Plan to the key stakeholders for their review and input. Stage 4 involves completion of the decommissioning works. A final surface survey is required on completion of these works as part of the 'as-built' drawings and final As-Built Decommissioning Report, for subsequent submission to the regulators.

The overall objective of all decommissioning operations is to gain relinquishment and remove liability (Stage 5). This point is achieved when the company achieves the agreed completion criteria for the TSF decommissioning (as agreed with key stakeholders). This is likely to require a period of active post-closure 
management over a broadly defined timeframe during which the required performance indicators are monitored.

\section{Conclusions}

The 2011 ANCOLD Guidelines highlight the important principle of designing, constructing and operating a TSF with an aim to an eventual closure strategy that will allow a safe and stable structure to remain following the completion of mining operations.

With the application of a risk management approach throughout the life of the TSF, the operator can effectively minimise, manage and control key risks, and potential design limitations and uncertainties can be mitigated if the outcomes of risk workshops are used to drive decisions on the future direction of the project.

Notwithstanding the considerable improvements the authors see in application of leading practice management techniques and planning processes, tailings decommissioning is still very much a collaborative teamwork exercise. Decommissioning is most effective if approached in a systematic way (with no short cuts), and requires a specific understanding of the physical, biogeochemical and geochemical nature of the specific tailings, the facility in which the tailings are stored, and a team of highly experienced people of the appropriate key scientific disciplines to effect a sustained and effective planned closure (Lacy and Barnes, 2006).

\section{References}

ANCOLD (2011) Australian National Committee on Large Dams. Draft Guidelines on Tailings Dams - Planning, Design, Construction, Operation and Closure, 34 p., viewed 16/07/2012, http://www.ancold.org.au/file/Tailings\%20Guidelinesb\%20v3\%20$\% 20$ Draft.pdf.

AS/NZS ISO 31000:2009 (2009) Risk management - Principles and Guidelines.

DEWHA (1992) Department of the Environment, Water, Heritage and the Arts. Intergovernmental Agreement on the Environment, viewed 10/07/2012, http://www.environment.gov.au/about/esd/publications/igae/index.html.

DITR (2007) Department of Industry, Tourism and Resources. Tailings Management, Leading Practice Sustainable Development Program for the Mining Industry 88 p., viewed 30/06/2012, http://www.ret.gov.au/resources/Documents/LPSDP/LPSDPTailingsHandbook.pdf.

DRET (July 2011) Department of Resources, Energy and Tourism. A Guide to Leading Practice Sustainable Development in Mining, Leading Practice Sustainable Development Program for the Mining Industry, 210 p., viewed 30/06/2012, http://www.ret.gov.au/resources/Documents/LPSDP/guideLPSD.pdf.

Envec, Environment Security Initiative (2005) Mining for Closure. Policies and Guidelines for Sustainable Mining Practice and Closure of Mines, South East Europe, UNEP, UNDP, OSCE, NATO.

Environment Australia (1999) Environmental risk management, Best Practice Environmental Management in Mining Series, Environment Australia, Canberra.

ICOLD (2001) International Commission on Large Dams. Bulletin 121 on Tailings Dams - Risk of Dangerous Occurrences.

ICOLD (2010) International Commission on Large Dams. Bulletin 153 on Sustainable Design and Post-Closure Performance of Tailings Dams, currently.

Jones, H., Lacy, H. and Watkins, R. (2006) Reclamation/rehabilitation and closure of tailing storage facilities, in Paste and Thickened Tailings - A Guide, 2nd edition, R.J. Jewell and A.B. Fourie (eds), Australian Centre for Geomechanics, Perth, Sec 11.8.

Lacy, H. and Barnes, K. (2006) Tailings Storage Facilities Decommissioning Planning is vital for successful closure, in Proceedings First International Seminar on Mine Closure (Mine Closure 2006), A.B. Fourie and M. Tibbett (eds), 13-15 September 2006, Perth, Australia, Australian Centre for Geomechanics, Perth, pp. 139-148.

Lacy, H. and Campbell, G. (2000) Decommissioning Tailings Storage Facilities: The challenges and how they are being met during closure of a NickelSulphide Mine in Western Australia, Minerals Council of Australia, 4th International and 25th National Environmental Workshop (2000), Conference Proceedings Perth, Western Australia.

Lacy, H. and Ward, J. (1998) Rehabilitation in relation to decommissioning of tailings storage facilities in Western Australia: challenges and solutions, in Short Course Proceedings Tailings Management and Decommissioning (Course No. COR 9810), December 1998, Perth, Australia, Australian Centre for Geomechanics, Perth.

MCMPR/MCA (2003) Ministerial Council on Mineral and Petroleum Resources; Minerals Council of Australia. Strategic Framework for Tailings Management, National Capital Printing, Canberra.

UNWCED (1987) United Nations World Commission on Environment and Development. Our Common Future, Oxford: Oxford University Press.

WMI (1994) Whitehorse Mining Initiative. Environment Issues Group, Final Report, October 1994 (as referenced in ANZMEC/MCA, 2000). 